\title{
The realistic dose concept applied to radiological assessments in NORM industries
}

\author{
B. Robles, J.C. Mora, C. Trueba and D. Cancio \\ Radiological Protection for the Public and Environment Unit, CIEMAT, \\ Avda. Complutense 22, 28040 Madrid, Spain
}

\begin{abstract}
The Spanish law that transposes the European Directive 29/96 is based on the recommendations established by ICRP in 1991. This law requires that estimations of the doses due to radioactive emissions, from practices or installations in which ionising radiation sources are used, must be performed in a regular base and in the more realistic possible way. More recently, the ICRP, as well as the European Union, recommended that, in order to reach a realistic estimation, a gradual approach made by consecutive iterations should be made. However, in spite of the huge amount of documentation, realistic dose assessments are usually treated just for artificial radionuclides, being Naturally Occurring Radioactive Materials (NORM) industries only considered by regulation, regarding to the necessity of performing studies to determine if there is or is not a significant increase in the exposition to the workers or to the public. In this paper an adaptation of the general criteria used to carry on realistic dose assessments for the particular case of NORM is presented. Also the difficulties and implications, that applying such criteria involve, are analysed. In addition the main parameters, which could influence the uncertainty of the assessment, are discussed.
\end{abstract}

\section{INTRODUCTION}

The Spanish Royal Decree 783/2001 [1] transposes the European 29/96 Directive [2] which is based on the recommendations established by ICRP in 1991 [3]. This law requires that estimations of the doses due to radioactive emissions, from practices or installations in which ionising radiation sources are used, must be performed in a regular base and in the more realistic available way. In particular, these realistic assessments should be performed when comparing the dose constraints fixed by the pertinent regulatory body.

More recently, the ICRP within its 101 report [4] and in the new recommendations [5], as well as the European Union in the Radiation Protection 129 report (RP-129) [6], recommended that, in order to reach a realistic estimation, a gradual approach made by consecutive iterations should be made. The aforementioned document RP-129 also establishes a generic methodology to obtain realistic doses in the evaluations. Another recommendation in those documents establishes that the intrinsic uncertainties of the results, if possible, should be estimated and discussed when performing a realistic dose evaluation.

However, in spite of the huge amount of documentation, realistic dose assessments are usually treated just for artificial radionuclides, being Naturally Occurring Radioactive Materials (NORM) industries only considered by regulation, regarding to the necessity of performing studies to determine wether it is or is not a significant increase in the exposition to the workers or to the public. Nevertheless, the performance of such studies should be based on the same criteria applicable to practices that use ionising radiation sources.

In this paper an adaptation of the general criteria used to carry on realistic dose assessments for the particular case of NORM industries is presented. The difficulties and implications, that applying such criteria involve, are also analysed. 


\section{METHODOLOGY TO ASSESS REALISTIC DOSES}

The overall goal of the realistic dose assessments is to calculate doses as close as possible to those that the individuals would actually receive due to the impact of a particular installation [6]. Achieving this goal is not easy as it seeks to avoid significant overestimates or underestimates and requires the implementation of successful approaches. For this purpose, the following steps are considered:

Identification and quantification of the source term.-the type and amount of each emitted radionuclide must be known, as well as the nature and location of the emission. The physicochemical form of the radionuclides must also be known, as it is likely to have a significant effect on the dose.

Data collection in the environment. - in order to determine the activity concentrations in the various components that form the environment, such as air, water and food. When possible, measurements should be used as initial data.

Identification of the exposure pathways and their relative importance.-the individuals can be exposed to radiation in different ways depending on the chemical and physical properties of the involved elements.

Identification of the exposed groups. - these could be either a reference group or a representative individual. It is also necessary to study and define the lifestyle and habits of these groups or individuals.

Dose assessment. - for which it is necessary to use adequate mathematical models and codes and finally make use of the dose conversion coefficients which relate concentrations in air or soil with the external component of effective dose rates, or those which transform a unit of intake to the internal component of the committed effective doses.

\section{IMPLICATIONS IN THE IMPLEMENTATION OF THE REALISTIC DOSE ASSESSMENT TO NORM INDUSTRIES}

The application of this methodology to NORM industries presents a number of peculiarities and difficulties different to its implementation in the case of nuclear and radioactive installations. The first, and perhaps the most important one, is based on the fact that the involved radionuclides are natural, and hence are the same ones that are present in the undisturbed environment. Based on the experience gained in applying this methodology in a NORM industry in Spain [7], for each stage several key points can be highlighted.

\subsection{Source term}

To make a radiological characterization of the raw materials and the waste or by-products of the industry is necessary. As it is also necessary to know the quantity of emitted radionuclides and their physicochemical form, because in the case of industries not considered radioactive, this information is normally not available.

Therefore, it is necessary to make a representative sampling of the raw materials, bearing in mind that, in many cases, the radioactive contents of these, and of their by-products, may not be uniform, because differences can exist in the radioactive contents of the sources (e.g. in coal, zirconium sand, etc.). Likewise it is also necessary to take samples of the effluents, including airborne filters and liquid from waste treatment systems.

It is also necessary to know the conditions under which the transformations of raw materials, and may be the waste or by-products of the production chain, occurs, because the chemical reactions and the conditions of pressure and temperature can lead to losses, enrichment and deposit of some radionuclides [8]. It is necessary to take into account that both mining and transportation as well as the industrial processing in NORM industries, could break the existing equilibrium in natural radioactive chains and, therefore, the assessment may not be valid from the measured activity of a single radionuclide in the chain. 


\subsection{Activity concentrations in the environment}

Obviously it is preferable to asses the effective dose by means of in situ measurements of ambient dose equivalent rate and radionuclide activity concentrations in the different compartments of the environment. The difficulty in NORM industry studies is mainly to distinguis between the natural radioactive background and the radioactivity coming from the operation of the particular NORM industry. Therefore sampling should be carried out both in the area of influence of the facility and in the area where should not be expected any influence, in order to subtract the natural background radiation to evaluate the effective dose. As usually the addition to natural radionuclides from this industry to the background was accumulated during decades before a radiological evaluation is performed, it is quite impossible to discriminate its contribution by means of measurements only. Moreover, if the increase is not very acute, the values obtained in the samples are usually of the same order of magnitude that the natural background in the vicinity. In these cases the use of models to simulate the transport and transfer of natural radionuclides in the different compartments of the environment is obviously necessary to evaluate effective doses.

\subsection{Exposure pathways and exposure groups}

The selection of the exposure pathways in order to differentiate between the public and workers is necessary. These workers are not considered as professionally exposed in the NORM industries, and for them to consider the different tasks that workers carry out in the industry is important, as the working conditions in them. Also, to verify where tasks are performed automatically, or if the operators are within rooms with separate ventilation, or if they use personal protective equipment (PPE), among others, is important. Finally to consider when internal, external or both types of exposure in each of the selected worker groups are important enough, should be identified.

In the case of the most exposed groups of population, the selection of the exposure pathways and reference groups is similar to that of nuclear and radioactive installations.

\subsection{Effective dose assessment}

The evaluation of the effective dose will be conducted using a combination of measurements, modelled data and reasonable assumptions. The models used to predict concentrations of activity in air and in the ground should use site specific meteorological data and preferably averaged from the values of several years. These meteorological data should also be used to locate the area (or areas) of "no influence" of the facility in order to measure there the value to be considered natural background.

Moreover, to determine in an empirical base the occupancy times in the different locations of the facility is crucial, in order to perform in a realistic way the dose assessment of workers. The total working day should not be used as a default value for the assessments if seeking realistic values. As noted before, it is also necessary to take into account the PPE used by operators, such as masks, knowing, or at least estimating, the particle size they retain and their effectiveness. To assess the inhalation component to the effective dose, it is necessary to know, or at least to make a reasonable estimation, the activity median aerodynamic diameter (AMAD) of the airborne particles in the workplaces. Therefore, when possible, AMAD measurements should be carried out.

To evaluate the external component of the effective doses due to raw materials, wastes or by-products accumulated within the facility or during their transportation, it is important to know as precisely as possible the time that the operators are exposed to them (e.g. the transport times).

As the assessments are performed in a progressively more realistic way, estimates and discussion should be made of the uncertainties inherent in the results. For this reason should be considered than dose evaluations necessarily involve assumptions to complete the knowledge, as the transfer factors of radionuclides in the specific environment or the behaviour of each radionuclide in natural chains in the 
industrial process. Moreover, effective doses are estimated by using measurements, applying models, or through a combination of both. The variabilities and uncertainties of the empirical data used contribute to define a distribution of possible effective dose values where its degree of variability and uncertainty will be defined by the shape and range of the distribution.

\section{CONCLUSIONS}

Experience in the application of the realistic dose assessment methodology in NORM industries, has demonstrated the importance of taking as much measurements as possible in raw materials, by-products, in the generated wastes and in every compartment of the environment. These measurements must be supplemented by modelling when necessary. The need to know the actual conditions in the different tasks performed by the operators has been also highlighted, in order to define the main exposure pathways and in this way to calculate in a realistic way effective doses, which should be finally compared with the reference effective dose levels.

\section{References}

[1] Real Decreto 738/2001 de 26 de Julio de 2001. "Reglamento para la protección sanitaria contra radiaciones ionizantes". BOE 178, 2001.

[2] CEC. "Council Directive 96/29/EURATOM: laying down basic standards for the protection of the health of workers and the general public against the dangers arising from ionising radiation". Official Journal of the European Communities L159, 1996.

[3] ICRP 1991 "1990 Recommendations of the International Commission on Radiological Protection”. Volume 21, 1-3, 1991.

[4] ICRP 101. "Assessing Dose of the Representative Person for the Purpose of Radiation Protection of the Public and The Optimisation of Radiological Protection: Broadening the Process". Volume 36, 3, 2006.

[5] ICRP 103. "Recommendations of the International Commission on Radiological Protection". Volume 37, 2-4, 2008.

[6] Radiation Protection 129. "Guidance on the realistic assessment of radiation doses to members of the public due to the operation of nuclear installation under normal conditions". European Communities, 2002.

[7] Baeza A., Calcio D., Corbacho J.A., Guillén J., Miralles Y., Mora J.C., Robles B., Suáñez A.Y. and Vasco J. "Estudio del impacto radiológico de las centrales térmicas de carbón sobre sus entornos". Unidad de producción térmica de Teruel. Colección documentos Ciemat. 2007.

[8] Huijbregts W.M.M., de Jong M.P. and Timmermans C.W.M. "Hazardous accumulation of radioactive lead on the water wall tubes in coal-fired boilers". Anti Corrosion Methods and Materials. 47-5: 274-279, 2000. 